\title{
RECONSTRUCTION STRATEGIES FOR SWMM-BASED CAMPUS LANDSCAPE STORMWATER MANAGEMENT
}

\author{
ZEXIN LEI, JUNJIE LUO \& LEI CAO \\ Department of Landscape Architecture, School of Architecture, Tianjin University, China
}

\begin{abstract}
Applying green stormwater infrastructure (GSI) to Tianjin University campus landscaping can not only reduce the negative impact of water runoff, but also improve the landscape environment for students. The campus also faces the risk of flooding, like other parts of the city of Tianjin, China. Different GSI layouts may be able to change the effective impervious area (EIA) without changing the total impervious area. Therefore, a reasonable GSI layout is critical for the efficiency of rainwater and flood management. Taking the Youth Lake area of Tianjin University as our research object, we set three scenarios separately, based on the storm water management model (SWMM), so the EIA area decreases thanks to an optimized GSI layout. Runoff and concentration models of scenarios under different rainstorm return periods were established by combining geographic information system with SWMM. Based on runoff analyses, peak discharge, peak times and the hydrological response of various drainage outlets in the diverse scenarios, we found that runoff can be reduced over $20 \%$ by only using GSI of $10 \mathrm{~cm}$ depth sunken green space and permeable pavement. If linear measurement of GSI such as a planting ditch, blind pipe and drainage pipe continue to be used to connect the impervious area with surrounding green space, the hydrological response will be further weakened, especially when the linear GSI is not placed parallel to the runoff direction. The same results as found by other studies leads us to conclude that following rainstorm events, upgrading weakens GSI control ability, even though GSI layout optimization was completed. We proved the key optimization strategy for GSI layout is intervention regarding runoff direction. Although campus needs a large concentrated hardened area to meet needs of students' daily activities; selection of GSI suitable for shape and location, especially using linear measures, can reduce EIA, accelerating the runoff attenuation process and reducing the campus flood risk.

Keywords: campus landscape reconstruction, green stormwater infrastructure (GSI), layout optimization, effective impervious area (EIA), hydrological response, storm water management model (SWMM).
\end{abstract}

\section{INTRODUCTION}

In China, stormwater management technology is known as "sponge city" construction. Some universities have taken the lead in using green stormwater infrastructure (GSI) to cope with drainage problems and improve the quality of their landscape environment [1]-[5]. By simulating natural hydrological processes, GSI can improve the water permeability and rainwater storage capacity of catchment areas, and increase the attenuation process for rainwater runoff. That is helpful to reduce the discharge and delay the flood peak. The renovation of campus landscapes provides an opportunity for GSI application, which can then provide reference for the development of cities and regions, in terms of making environmental policies [6], [7].

A variety of methods have been used in campus landscape design, guided by stormwater management, including the innovation and installation of new water storage areas [8]; the designing of the green roof, green wall, rain garden and other ecological landscaping [9]; and the selection and application of drought and waterlog-tolerant plants [10]. Those are effective ways to solve campus rainwater issues. The application of GSI to these campus landscapes mainly focuses on the type, quantification, materials and landscape morphology; as they 
directly affect runoff infiltration capacity. Yet application of GSI still lacks more detailed consideration on how to arrange and apply it properly.

Runoff and confluence in part of the impervious areas can result in flooding pressure [11]. But such a problem can be eliminated by improving the connectivity of impervious underlying surfaces, and reducing the number and areas of EIA [12]. In addition, campus landscape design needs to take both functions and ecological protection into consideration [13], to provide a better environment for students. The application of GSI and its optimized layout can improve ecological resilience to a certain extent, while at the same time, solve the rain and flood problems. With the deepening of our research, we need more accurate quantitative models to guide the practice of landscape design [14]. During campus rainwater management, it is necessary to complete a system simulation and special evaluation of rainfall, runoff, site infiltration capacity, water storage capacity [15] and water quality change [4], so that the measure's effect can be predicted. Previous studies show that EIA can explain the green space system layout for urban stormwater control [16]. Besides, the storm water management model (SWMM) is also an excellent model software for urban stormwater layout simulation with Low Impact Development (LID) [17], [18]. Although the dimension of the campus area is relatively smaller than an urban area, it could be more accurate to simulate the details of site drainage and cope with the rain and flood issues purposefully, by combining the Geographic Information System (GIS) with SWMM [19]-[22].

In order to get the GSI layout strategy to improve stormwater management efficiency by controlling the runoff path and reducing EIA, we performed this study. Under the same land use status, three scenarios with EIA reduced in turn were run in SWMM. By comparing the results of the hydrological response, the efficiency of stormwater management in the three scenarios was judged, and the optimization strategy for GSI was obtained.

\section{STUDY AREA}

The past decades saw the reconstruction of the old campus of Tianjin University. A large number of ponds on the campus were filled in and the ground was hardened. There are only four large ponds left, built into artificial lakes: Jingye Lake, Aiwan Lake, Youyi Lake and Youth Lake, the largest and deepest. The drainage outlets of the first three lakes are connected in series, and this water could finally discharge into Youth Lake. The outlet for Youth Lake is directly connected with the municipal drainage network [10]. In this way, the drainage of campus during flood season is guaranteed.

Along with elevation data, the current drainage network and roads data supported by GIS, the relatively independent and complete catchment area with Youth Lake at the center is delineated as our research area (Fig. 1(a)). This area is located in the north of the campus, having an area of about 21 hectares. The area's green rate is only about $17 \%$, where green space is relatively scattered. The western and northern sections of the area are dormitory areas, while the southeast part is close to the teaching and research area. The whole area is frequently used and crowded. As the main area for student activities, a large area of centralized hard ground is required. Therefore, the Youth Lake area has the largest number of waterlogging spots throughout the campus in the flood season, which urgently need landscape renovation to ensure functionality of the site and improve site drainage.

\section{DATA AND METHODS}

To accurately obtain the production and concentration zoning of the study area, computerassisted drafting (CAD) terrain data and rainwater pipe network information of Tianjin University were used as data sources. Through Watered Tool and Thiessen Method in 

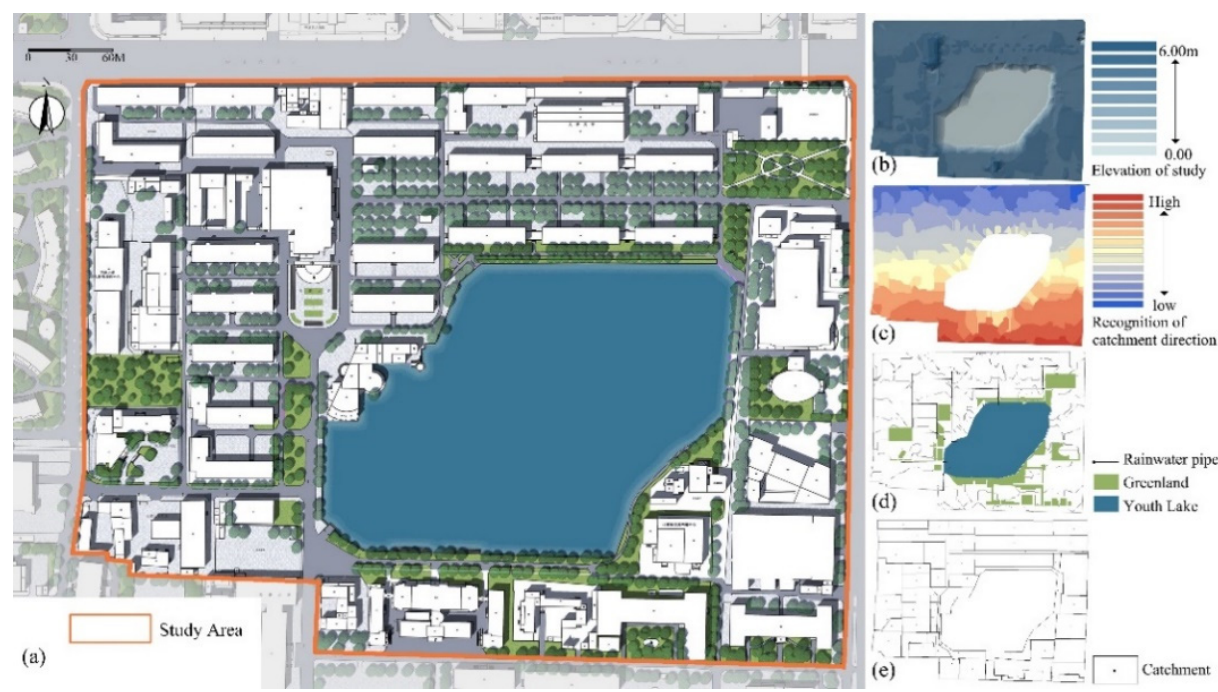

Figure 1: (a) Plan of Youth Lake area within the old campus of Tianjin University; (b)-(e) Identification of sub-catchments of our study area by GIS.

ArcGIS, combined with building location and elevation data, the water separation effect of buildings on the actual terrain was restored (Fig. 1(b)). Then we simulated runoff and confluence (Fig. 1(c)). Finally, the boundary of the sub-catchment area was modified by green space and water body (Fig. 1(d)), and the whole research area was divided into 59 subcatchment areas (Fig. 1(e)), with geometric properties added.

\subsection{SWMM settings}

Based on the site confluence situation found by multiple field explorations in different quarters, combined with the existing underground network data, the GIS data information for the sub-catchment area was imported into SWMM. A generalized model of the whole Youth Lake area was formed, made up of 59 sub-catchment areas, 34 nodes and six rainwater outlets, connected with 34 pipe sections, respectively (Fig. 2). Due to differences between the design flood level of Youth Lake and the ground elevation of the campus, and because the waters can be connected to the municipal pipe network, our model does not consider the existence of rainstorm overflow or backflow of the external pipe network into the lake.

We needed, for SWMM runoff simulation, a large number of input parameters: Most of the parameters used to define the characteristics of the surface and rainwater drainage network can be imported into SWMM in the form of a TXT file from GIS data; other parameters referring to the SWMM model were entered manually from existing research on SWMM modeling in Tianjin city [23], [24]. The Horton formula was used for infiltration calculation and the flow volume was calculated by dynamic wave method.

\subsection{Design for rainfall}

According to "Tianjin sponge city construction technical guidelines" [25], the Chicago rainstorm type is used in the design of rainstorm type. Considering our campus environment, 


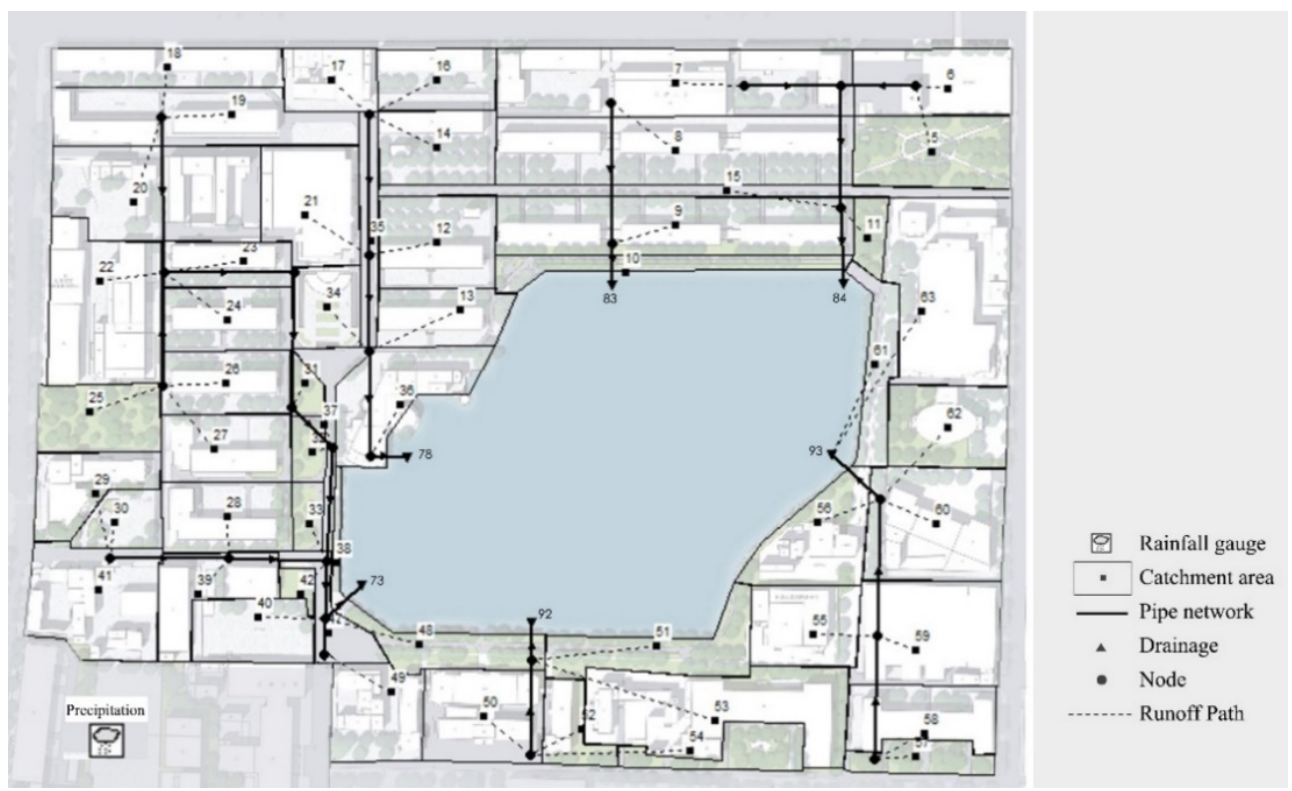

Figure 2: Generalized model of production and concentration in our study area.

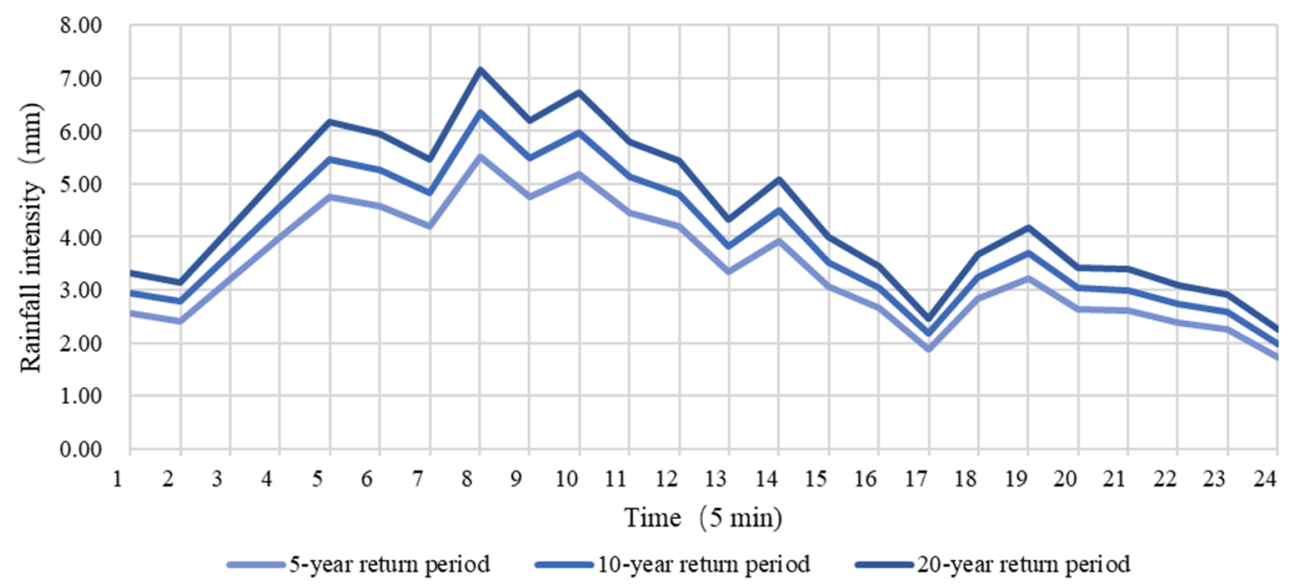

Figure 3: Design of 2-hour rainstorm within different return periods.

especially the living area, requires a higher level of rain and flood safety, so test rainfall was designed as follows: rainfall duration is for two hours and the return periods were 5, 10 and 20 years, respectively. Based on the above input parameters, the design of rainfall patterns with different return periods were obtained (Fig. 3). 


\subsection{Scenario scheme}

The common GSI measures, such as sunken green space, permeable pavement, biological retention facilities and grass planting ditches were selected to design three scenarios of runoff pathways. The current situation of land used in the study area was basically unchanged, to ensure adequate transportation and activity space for students. Situation descriptions:

S1. Current situation (Table 1, S1).

S2. GSI transformation scenario (Table 1, S2).

Adhering to the principle of not affecting the study area's functions, all the green spaces, including the roadside tree pool were changed into sinking green space with a $10 \mathrm{~cm}$ depth [26]. Biological retention facilities were added to the main, centralized, green lands. Besides, some centralized hard pavement sites were set up with permeable pavement. Accordingly, we added a LID control unit in the sub-catchment area of our SWMM model, and specific parameters referring to the recommended value in the SWMM model manual. In order to compare with S3, all GSI facilities (including biological detention facilities, tree pools, permeable pavement) in this scenario simulation were not provided with drainage pipes or blind pipes, so the connectivity of impervious areas was not changed. In other words, the GSI transformation in this S2 scenario has reduced the TIA proportion of the study object to a certain extent, but has not effectively reduced the proportion of EIA.

S3. EIA reduction scenarios (Table 1, S3).

On the basis of S2, structures such as planting ditches and blind pipes were added, to ensure that most of runoff from the impervious area can be introduced into the nearby green spaces or permeable areas. EIA is reduced in this way. Corresponding to the SWMM, on the one hand, the routing method was changed from "OUTLET" to "PERVIOUS" and the parameters of underground channels in LID were set. On the other hand, the confluence directions of some parts of the catchment area were adjusted appropriately, and the runoff was drained into adjacent green space, and then discharged into the rainwater pipe network.

Table 1: Summary of statistics of relevant landscape features of our three study scenarios (S1, S2, and S3).

\begin{tabular}{|l|c|c|c|}
\hline Landscape features & S1 & S2 & S3 \\
\hline Total impervious area (TIA) & $65.32 \%$ & $55.03 \%$ & $54.06 \%$ \\
\hline Effective impervious area (EIA) & $60.57 \%$ & $44.88 \%$ & $32.97 \%$ \\
\hline Green rate (including water body) & $33.43 \%$ & $34.76 \%$ & $35.73 \%$ \\
\hline Water body & $18.07 \%$ & $18.07 \%$ & $18.07 \%$ \\
\hline Sunken green space & 0 & $13.26 \%$ & $13.26 \%$ \\
\hline Biological detention facilities & 0 & $2.39 \%$ & $2.39 \%$ \\
\hline Grass planting ditch & 0 & $1.13 \%$ & $1.60 \%$ \\
\hline Permeable pavement & $1.25 \%$ & $10.21 \%$ & $10.21 \%$ \\
\hline
\end{tabular}

Accurate identification and direct measurement of EIA are complex [12]; however, thanks to the small scale of our study area, the attributes of each sub-catchment area in the SWMM model can be used to calculate the related landscape characteristics statistics of the three design scenarios. Table 1 compared with S1, the TIA of S2 and S3 as basically unchanged, but shows that EIA decreases in turn. And while the overall green space rate remained unchanged, the proportion of GSI increases. This means that the application of GSI did not transform the overall spatial pattern of the study area. 


\section{RESULTS AND DISCUSSION}

\subsection{Analysis of simulation results}

Based on SWMM, the hydrological response of three scenarios can be comprehensively evaluated from total runoff, total discharge and the change process of discharge at each outlet.

\subsubsection{Total runoff in the study area}

In the same rainstorm event, the surface runoff characteristics showed that S1 total runoff and outflow were the maximum values of the three scenarios (Table 2). Compared with S1 and S2, it is easy to find that the total runoff reduction exceeded one-fifth when the green space was sunken and the centralized hardened area was replaced by permeable pavement under the premise of basically land use being unchanged. Results of S2 and S3 showed that runoff can be guided by planting ditches, blind pipes, drainage pipes or other linear forms, which can reduce the connection of the impervious area, and the flow can thus be further reduced. With the decrease of EIA, the rainfall and flood pressure of the site will be relieved.

Table 2: Production and exchange flow of different scenarios in different return periods.

\begin{tabular}{|c|c|c|c|c|c|c|c|c|c|}
\hline & \multicolumn{3}{|c|}{\begin{tabular}{c} 
Runoff depth (mm) \\
\cline { 2 - 9 }
\end{tabular}} & \multicolumn{3}{|c|}{$\begin{array}{c}\text { Percentage of runoff } \\
\text { reduction (\%) }\end{array}$} & \multicolumn{3}{c|}{ Outflow (mm) } \\
\cline { 2 - 10 } & $\mathrm{P}=5$ & $\mathrm{P}=10$ & $\mathrm{P}=20$ & $\mathrm{P}=5$ & $\mathrm{P}=10$ & $\mathrm{P}=20$ & $\mathrm{P}=5$ & $\mathrm{P}=10$ & $\mathrm{P}=20$ \\
\hline S1 & 80.265 & 92.644 & 105.04 & - & - & - & 13.033 & 15.038 & 17.051 \\
S2 & 59.422 & 70.218 & 81.029 & 25.97 & 24.21 & 22.86 & 9.718 & 11.483 & 13.216 \\
S3 & 49.934 & 61.052 & 72.658 & 37.79 & 34.10 & 30.83 & 8.171 & 10.019 & 11.921 \\
\hline
\end{tabular}

$\mathrm{P}=$ return period in years, $\mathrm{S}=$ scenarios same as in Table 1 .

In addition, upgrading of rainstorm events weakens the control ability of S2 and S3 as GSI optimal projects. It means the effects of stormwater regulation by GSI or LID is limited by increasing rainfall, which is consistent with existing research results [20], [27].

\subsubsection{Total discharge into Youth Lake}

As an independent catchment area, runoff flows into Youth Lake directly or through the drainage outlet. Therefore, variation of the flood peak of Youth Lake can directly reflect the total discharge of the area. As seen in Table 3, the greater the rainfall, the higher the peak value and the earlier the peak time, the greater the runoff pressure on the pipeline and the surface; however, GSI can provide more space for runoff infiltration and storage. The reduction of EIA area increases retention time of rainwater in GSI, which is beneficial to reduce rain flood pressure of Youth Lake and reduce the flood risk of dormitory living areas.

Table 3: Drainage and acceptance of lake at different scenarios in different return periods.

\begin{tabular}{|c|c|c|c|c|c|c|c|c|c|}
\hline & \multicolumn{3}{|c|}{ Flow peak (CMS) } & \multicolumn{3}{c|}{ Time of flood emergence } & \multicolumn{3}{c|}{ Peak duration (min) } \\
\cline { 2 - 10 } & $\mathrm{P}=5$ & $\mathrm{P}=10$ & $\mathrm{P}=20$ & $\mathrm{P}=5$ & $\mathrm{P}=10$ & $\mathrm{P}=20$ & $\mathrm{P}=5$ & $\mathrm{P}=10$ & $\mathrm{P}=20$ \\
\hline $\mathrm{S} 1$ & 1.39 & 2.31 & 2.56 & $1 \mathrm{~h} 35 \mathrm{~min}$ & $55 \mathrm{~min}$ & $1 \mathrm{~h}$ & - & - & - \\
\hline S2 & 1.13 & 1.62 & 1.94 & $1 \mathrm{~h} 40 \mathrm{~min}$ & $1 \mathrm{~h} 5 \mathrm{~min}$ & $1 \mathrm{~h} 5 \mathrm{~min}$ & 5 & 10 & 5 \\
\hline S3 & 1.09 & 1.43 & 1.76 & $1 \mathrm{~h} 45 \mathrm{~min}$ & $1 \mathrm{~h} 15 \mathrm{~min}$ & $1 \mathrm{~h} 15 \mathrm{~min}$ & 10 & 20 & 10 \\
\hline
\end{tabular}


Table 3 shows that peak duration reaches the maximum value in the 10 -year return period rainfall events, while the duration of 5-year and 20-year return periods are the same. More efforts are needed to explore whether this phenomenon means that there is some nonlinear relationship between the rainstorm and the attenuation rate of storm water storage capacity.

\subsubsection{Flow process change at drain}

According to the SWMM simulation results, the discharge flow process lines of each drainage outlet (Fig. 4) were plotted, and the change trend could be divided into three situations (S1, S2 and S3):

1. The peak values of S1, S2 and S3 decreased in turn, and the peak current time did not change significantly (Fig. 4(a)).

2. The peak values of S1, S2 and S3 did not change much, but the peak current time moved back obviously (Fig. 4(b)).

3. The peak values of $\mathrm{S} 2$ and $\mathrm{S} 3$ decreased, but the overall hydrological response of S3 was weaker than S2 (Fig. 4(c)).

The different drainage outlet discharge performances were closely related to the relationship between GSI layout and runoff path. According to the SWMM, there were six sub-drainage zones, and the number of drainage outlets in Fig. 2 represent the drainage zone. The variation of three different flow processes studied can be further explained by sorting out the topological relationship of the neutron catchment area in each drainage area (Fig. 5).

1. There are a large number of fragmented green patches in drainage zones 73,84 and 93 . The site runoff and peak flow can be improved upon by adding GSI facilities. Due to the limited area of green space, proper use of grass planting ditches and blind pipes to connect the impervious areas with green spaces can reduce peak discharge, but has little influence on peak current time.

2. Drainage zones 83 and 92 are adjacent to the north and south bank of Youth Lake. Most EIAs in these two drainage areas are converted into ineffective impervious areas by a series of lakeside greenbelts, perpendicular to the runoff direction. After the runoff enters the belt greenbelt vertically, the volume of greenbelt depression, the vegetation and sandstone soil can regulate rainwater and delay the runoff flow into the drainage outlet, as well as the peak current time. Because all EIA in drainage zone 92 is converted, it reveals a better effect on peak reduction than zone 83 .

3. In drainage section 78 , the road runs through the entire section. As a typical EIA, the road guides rainwater into the drainage outlet 78 , along the site elevation and drainage network. In addition, the green rate in this area is low, and it could be reduced to some extent by adding GSI facilities appropriately along the road direction. But during the process of S3 setting, the rainwater runoff was adjusted, and the surrounding runoff was introduced into both sides of the road green space and downward square. As a result, in the case of a heavy rainstorm, S3 would instead cause more peak flow than S2.

\subsection{Layout method of GSI guided by runoff path optimization}

In different rainstorm return periods, runoff path simulation and hydrological response results of different scenarios were analyzed from three aspects: total runoff, total discharge and flow process change of six outlets. As the most common GSI measure, sunken green spaces and permeable pavement are very effective in reducing the stormwater pressure of our study site, dominated by impervious areas. The impervious area could be connected with the pervious 

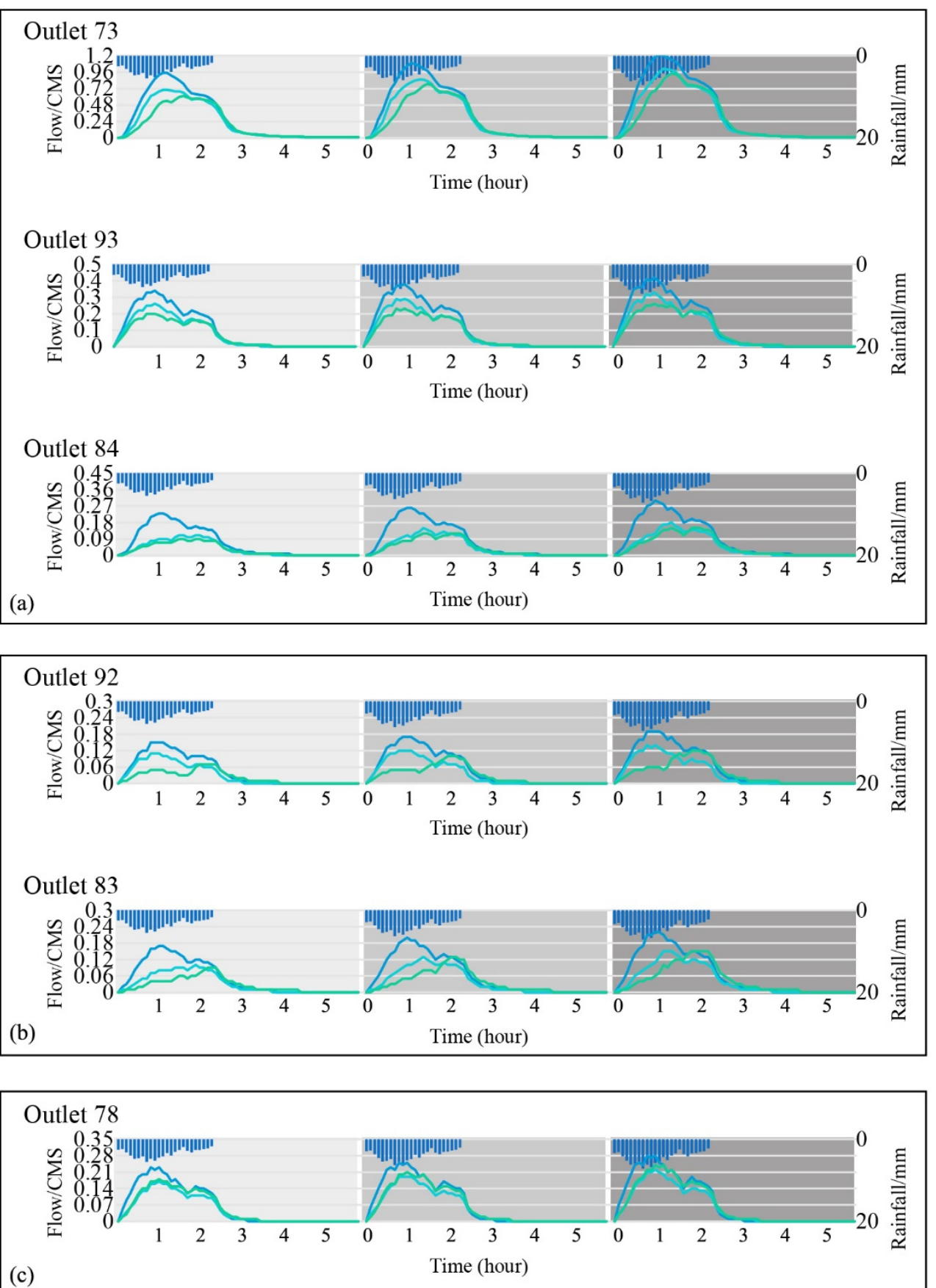

\begin{tabular}{lllr}
\cline { 3 - 3 } Rainfall & $\mathrm{S} 1$ & $\mathrm{~S} 2$ & $\mathrm{~S} 3$ \\
5-year return period & 10-year return period & 20-year return period
\end{tabular}

Figure 4: Line charts of discharge change process at drain outlets. 


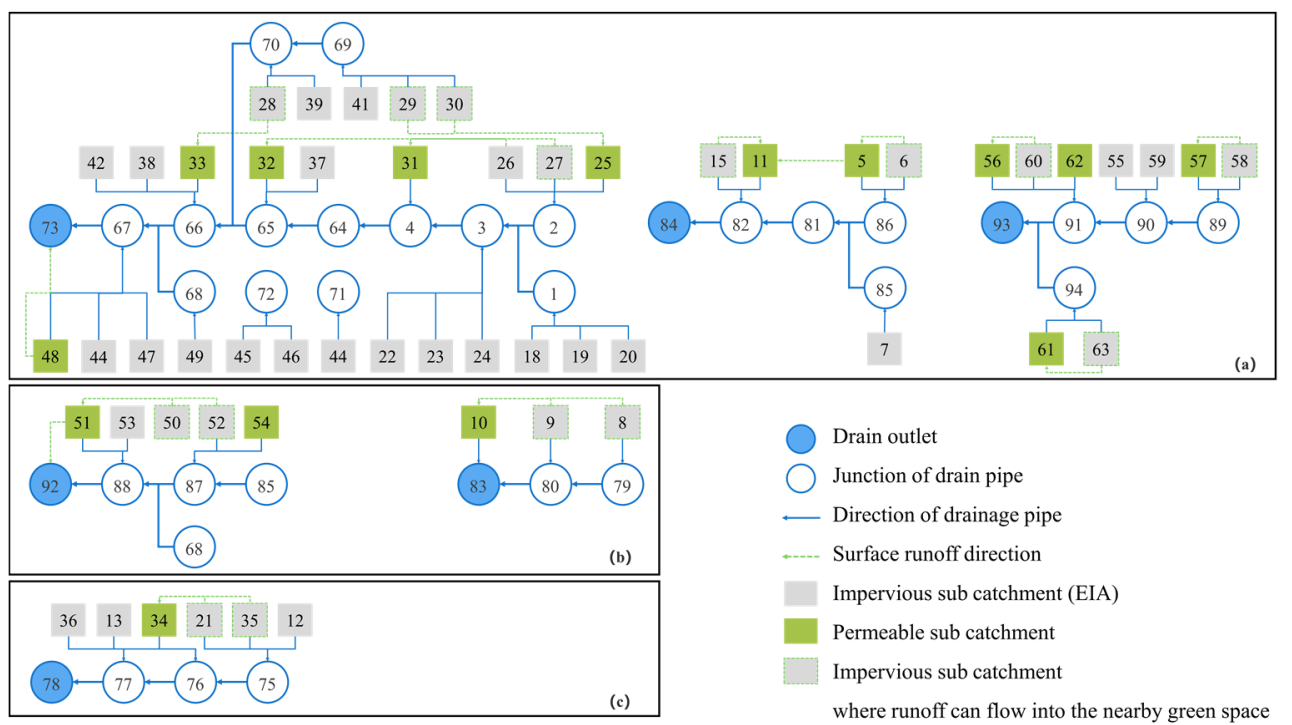

Figure 5: Site drainage area and topological relation of sub catchment area. EIA: effective impervious area.

area by drainage structures such as grass planting ditches, open channels, blind pipes, etc. This method can further reduce the site rainwater pressure in most campus areas; however, for some areas, such as roads, these methods are difficult to have make a positive impact. Therefore, the selection and layout of GSI must consider its relationship to the direction of runoff. For planar and dotted GSI measures such as sunken green lands, biological retention pools, rainwater gardens and seepage wells, their placement can effectively reduce environmental assessment and reduce the rainwater peak, if runoff can be cut off or blocked.

In addition, sufficient GSI measures can provide more flood storage space for the site, which has the obvious effect of delaying peak time; however, linear GSI measures, such as straw ditches and blind pipes, will have different effects on EIA conversion. On the one hand, linear measures can directly connect adjacent areas and improve drainage problems in impervious areas; but on the other hand, linear measures may increase the flood pressure across or at the end of runoff transport. Especially for impermeable linear areas, such as roads with large flow and high flow, barriers with adjacent impermeable areas should be increased to reduce inflow of peripheral runoff. Simply relying on sinking pools on both sides of the road to solve the problem of short-term rainwater accumulation on the road may, on the contrary, bring greater risk of waterlogging to the road, due to the height difference problem.

\section{CONCLUSIONS}

Most of the student activity areas on campus are hard paved. The traditional hardened site has a big problem with flooding. Also, it is urgent to update the landscape environment, for student use. Reducing EIA through optimizing the GSI layout is an effective measure to ensure rainwater and flood control under the demand of site use. In this paper, by means of multi-scene simulation in SWMM, we analyzed the relationship between the control site runoff path and that of our GSI layout, in a bid to control the EIA area and enhance the efficiency of site rainwater management. At the same time, the combination of GIS and 
SWMM provided a method for scientific and quantitative evaluation of the site's hydrological response.

However, we should also recognize some limitations. Firstly, the topographic changes and sub-catchment areas in different campus environment areas are complicated. SWMM parameters with higher accuracy need more future field research. Also, our study uses rainstorm events to simulate site rainstorm and flood, but it fails to consider the sensitivity of GSI under different rainfall conditions. In order to better explore the rainwater response resulting from the reduction of GSI and EIA, we note that groundwater level changes, evaporation and utilization efficiency of the current pipeline network are not included in the simulation process; however, because the rainfall time and pipe network system of the three scenarios were identical, the green area settings have had little change. The validity of the research results can be guaranteed by controlling variables.

This study proposed a green infrastructure layout strategy to optimize the water runoff path and reduce the effective impervious area for the activities space, in the impervious area on campus, to reduce the risk of site flooding. That could help provide some plans for stormwater management in an urban hard activities area with complex functions such as our campus, through the method of model coupling and use of the grey-green combination in future research.

\section{REFERENCES}

[1] Cao, W., Zhang, B. \& Huang, K., Campus sponge transformation scheme based on SWMM model. China Water and Wastewater, 34(15), pp. 122-126, 2018.

[2] Zhang, X. et al., Exploration on sponge reform scheme of Xiaocuo Primary School in Xiamen city. Water and Wastewater Engineering, 45(6), pp. 59-62, 70, 2019.

[3] Liu, L. et al., Practice of sponge transformation method of mountainous type campus into a sponge city. China Water and Wastewater, 35(12), pp. 71-76, 2019.

[4] Cui, H. et al., Rainwater utilization and WASP simulation evaluation on green campus. China Water and Wastewater, 34(21), pp. 127-132, 2018.

[5] Xu, H. et al., Sponge ecological landscape design and benefit analysis of campus green space in Nanchang city. 2018 International Conference on Zoology, Botany and Ecology, ed. S. Zhou, pp. 21-24, 2019.

[6] Zaharova, T.V., The effectiveness of environmental policy: From solving global problems to establishing university campuses. Vestnik Tomskogo Gosudarstvennogo Universiteta-Filosofiya-Sotsiologiya-Politologiya-Tomsk State University Journal of Philosophy Sociology and Political Science, 47, pp. 179-188, 2019.

[7] Narine Torres, M. et al., A participatory approach based on stochastic optimization for the spatial allocation of sustainable urban drainage systems for rainwater harvesting. Environmental Modelling and Software, p. 123, 2020.

[8] Tummala, C.M. \& Dittrich, T.M., Evaluating the effectiveness of bioswales and catch basin inserts for treating urban stormwater runoff in Detroit, Michigan. World Environmental and Water Resources Congress 2019: Water, Wastewater, and Stormwater; Urban Water Resources; and Municipal Water Infrastructure, eds G.F. Scott \& W. Hamilton. pp. 124-131, 2019.

[9] Kurtaslan, B.O., Examination of Selcuk University Alaaddin Keykubat Campus in the context of ecological landscape design. Journal of Environmental Biology, 41(2), pp. 463-474, 2020.

[10] Kurtaslan, B.O., Demirel, O. \& Konakoglu, S.S.K., Investigation of Selcuk University campus landscape design in terms of water efficient landscape arrangement. Journal of Environmental Protection and Ecology, 20(4), pp. 2130-2140, 2019. 
[11] Wei, Z. et al., The inspiration of rainwater utilization of foreign sponge campus landscape planning for Beijing. Third International Conference on Energy Engineering and Environmental Protection, 2019.

[12] Epps, T.H. \& Hathaway, J.M., Establishing a framework for the spatial identification of effective impervious areas in gauged basins: Review and case study. Journal of Sustainable Water in the Built Environment, 4(2), 05018001, 2018.

[13] Aalto, H.E., Marcus, L. \& Torsvall, J., Towards a social-ecological urbanism: Coproducing knowledge through design in the Albano Resilient Campus Project in Stockholm. Sustainability, 10(3), 2018.

[14] Sultana, R. \& Baconawa, M., Performance analysis of rainwater tanks at California State University Long Beach. World Environmental and Water Resources Congress 2019: Water, Wastewater, and Stormwater; Urban Water Resources; and Municipal Water Infrastructure, eds G.F. Scott \& W. Hamilton, pp. 7-13, 2019.

[15] Saeedi, I. \& Goodarzi, M., Rainwater harvesting system: A sustainable method for landscape development in semiarid regions. The case of Malayer University campus in Iran. Environment Development and Sustainability, 22(2), pp. 1579-1598, 2020.

[16] Yunlu, Z. et al., Study on green space stormwater management planning based on urban green space system optimization: A case study of Tongliao. Urban Development Studies, 25(1), pp. 97-102, 2018.

[17] Dongdong, Y. et al., Research of urban community road system layout optimization strategy based on simulation analysis of generation and concentration. Landscape Architecture, 26(10), pp. 101-106, 2019.

[18] Shulan, S. et al., Urban stormwater simulation based on recognition of effective impervious area. Journal of Beijing Normal University (Natural Science), 55(5), pp. 595-602, 2019.

[19] Shanshan, M. et al., Analysis of peak flow reduction with green roof and sunken lawn applied in series. China Water and Wastewater, 30(3), pp. 101-105, 2014.

[20] Song, L., Jiayi, M. \& Jie, S., Hydrology evaluation of green stormwater infrastructure based on SWMM: Case study on Tongji University campus. Landscape Architecture, 2017(1), pp. 60-65, 2017.

[21] Peng, Z. et al., Urban stormwater and flood control effect of green and grey infrastructures under extreme rainfall conditions. China Environmental Science, 39(5), pp. 2123-2130, 2019.

[22] Yizhang, Z. \& Hailong, L., Research on stormwater management and landscape design of Xinmin Road in Tsinghua Campus based on low impact development. Construction Science and Technology, 2019(Z1), pp. 61-68, 2019.

[23] Liujun \& Xiangyang, X., Application of urban rainfall flood model in analysis and calculation of drainage in Tianjin. Haihe Water Resources, 2001(1), pp. 9-11, 2001.

[24] Wanting, L., Dongmei, S. \& Ping, F., Simulation study on influence of low impact development measures on rainstorm runoff in Tianjin Municipality. Journal of Natural Disasters, 26(3), pp. 156-166, 2017.

[25] Tianjin Urban and Rural Construction Committee, Tianjin sponge city construction Technical Guidelines, 1 Apr. 2016. http://zfcxjs.tj.gov.cn/ztzl_70/bzgf/xxbz/xxbzgf/.

[26] Guoping, X. et al., Effectiveness analysis on storage and infiltration rates of concavedown green space in Tianjin city. Bulletin of Soil and Water Conservation, 32(6), pp. 120-122, 128, 2012.

[27] Zhuoxi, L., Huapeng, Q. \& Kun, X., Hydrological effect analysis of low impact development under different rainfall conditions. China Water and Wastewater, 28(21), pp. 37-41, 2012. 